\title{
Ocular parameters before and after steep Trendelenburg positioning for robotic-assisted laparoscopic radical prostatectomy
}

This article was published in the following Dove Press journal:

Clinical Ophthalmology

13 September 2017

Number of times this article has been viewed

\author{
Kyoichi Mizumoto' \\ Masahiko Gosho \\ Masayoshi Iwaki' \\ Masahiro Zako ${ }^{3}$ \\ 'Department of Ophthalmology, \\ Aichi Medical University, Nagakute, \\ Aichi, Japan; ${ }^{2}$ Department of Clinical \\ Trial and Clinical Epidemiology, \\ Faculty of Medicine, University of \\ Tsukuba, Tsukuba, Ibaraki, Japan; \\ ${ }^{3}$ Department of Ophthalmology, \\ Asai Hospital, Seto, Aichi, Japan
}

Correspondence: Masahiro Zako Department of Ophthalmology, Asai Hospital, I78-I Yakata-cho, Seto, 489-0866 Aichi, Japan

$\mathrm{Tel}+8 \mid 56$ I84 3III

Fax $+8 \mid 561848772$

Email mzako@aol.com
Purpose: Intraocular pressure (IOP) increases in patients in a steep Trendelenburg position during robotic-assisted laparoscopic radical prostatectomy (RALP). We hypothesized that a steep Trendelenburg position during RALP, an unusual systemic condition involving a transiently increased IOP, may induce ocular pathology that can be detected by detailed evaluations long after the surgery. This study aims to explore ocular structural and functional parameters in patients before and in the long term after the surgery.

Patients and methods: A comparative observational study was performed. A total of 44 eyes of 22 male patients scheduled for RALP at Aichi Medical University from August 2012 to July 2013 were included. Clinical parameters before and after RALP were compared. Perioperative IOP was measured immediately post-induction of anesthesia in the flat supine position (T1), immediately post-steep Trendelenburg position (T2), and prior to returning to a flat supine position while in a steep Trendelenburg position (T3). The thicknesses of the peripapillary retinal nerve fiber layer, ganglion cell complex (GCC), and central fovea were measured with spectral domain optical coherence tomography. Humphrey perimetry was performed before and at 3 and 6 months after surgery.

Results: The average IOPs $(\mathrm{mmHg})$ at each stage were $\mathrm{T} 1=10.4, \mathrm{~T} 2=21.7$, and $\mathrm{T} 3=29.6$, and differed significantly. The mean visual acuity (logarithm of the minimal angle of resolution), IOP, mean deviation, and pattern standard deviation measured by the Humphrey field analyzer showed no statistically significant difference before and after surgery. The ganglion cell complex and retinal nerve fiber layer thicknesses measured at each location and the central fovea thicknesses measured before and after surgery did not differ significantly.

Conclusion: No significant disorders in ocular structural and functional parameters were found until long after RALP.

Keywords: retinal nerve fiber layer, spectral domain optical coherence tomography, steep Trendelenburg position, Humphrey perimetry, robotic-assisted laparoscopic radical prostatectomy

\section{Introduction}

Robotic-assisted laparoscopic radical prostatectomy (RALP), one of the newest and most technically advanced treatments for prostate cancer, requires specific body positioning of the patient in a steep Trendelenburg position, which ideally enables gravity to pull the abdominal viscera away from the operative field. However, this position may have unfavorable physiologic effects when held for extended period, with reports describing adverse effects on visual function or postoperative visual loss as complications of the surgery. ${ }^{1-4}$ One patient has become bilaterally blind following a RALP in the steep Trendelenburg position, without observed hypotension, 
hemodilution, metabolic disturbance, or extreme blood loss. ${ }^{2}$ Another patient developed ischemic optic neuropathy (ION) after the robotic-assisted procedure. ${ }^{1}$

Intraocular pressure (IOP) increases when patients are placed in the steep Trendelenburg position (head down $\left.25^{\circ}-45^{\circ}\right),{ }^{2,4,5-7}$ and the IOP reaches peak levels at the end of the RALP in this position. ${ }^{4,5,7}$ Acute primary angle closure and a steep Trendelenburg position during RALP are similar in respect to a transient increase in IOP, although the situations differ. An acute primary angle closure is regarded as only a local ocular pathology, but a steep Trendelenburg position during RALP is relevant to systemic situations such as anesthesia and circulation. Retinal nerve fiber layer (RNFL) thickness becomes thinner with time from onset to 6 months after an acute primary angle closure, ${ }^{8,9}$ and perimetric defects have been found after a single acute angle closure glaucoma attack. ${ }^{10}$ On the other hand, visual function and RNFL thicknesses show no significant change at 1 month after RALP. ${ }^{7}$ Taketani et al, however, demonstrated transient, but significant visual field defects after RALP, ${ }^{4}$ implying the presence of unexamined abnormal ocular parameters.

In this study, we hypothesized that a steep Trendelenburg position for RALP, an unusual systemic condition with a transiently increased IOP, may induce ocular pathology that can be detected by detailed evaluation long after surgery. As ocular structural parameters, we evaluated RNFL, ganglion cell complex (GCC), and central foveal (CF) thicknesses by detailed retinal sections with spectral domain optical coherence tomography. As ocular functional parameters, we evaluated mean deviation (MD) and pattern standard deviation (PSD) with the Humphrey field analyzer. We compared these parameters before and at 3 and 6 months after surgery in this first report to analyze the detailed ocular parameters for the longest known period after the operation.

\section{Patients and methods}

\section{Patients}

This was a single-center, prospective, nonrandomized observational study. Twenty-two consecutive patients scheduled for RALP were recruited at Aichi Medical University from August 2012 to July 2013. Patients were excluded if they had preexisting glaucoma and retinal vascular diseases that could affect neuroretinal function or corneal diseases that could affect the IOP measurement. Ocular structural and functional parameters were evaluated in patients before and after steep Trendelenburg position (head down $30^{\circ}$ ) during RALP. Patients scheduled for prostatectomy visited our ophthalmology department 1 month before and 3 and 6 months postoperatively. A complete ophthalmic examination was performed at each visit that included determining the best-corrected visual acuity (BCVA), IOP measurement in sitting position using a slit lamp-mounted Goldmann applanation tonometer, slit lamp biomicroscopy, indirect ophthalmoscopy, color fundus photographs, spectral domain optical coherence tomography (SDOCT), and automated perimetry using a Humphrey field analyzer. The BCVA was determined with the Snellen chart, and the logarithm of the minimal angle of resolution value was calculated for statistical analysis. An outlined time course to show when each measurement was performed is summarized in Figure 1.

All procedures performed in studies involving human participants were in accordance with the ethical standards of the Institutional Review Board of the Ethics Committee of Aichi Medical University Hospital and with the 1964 Declaration of Helsinki and its later amendments. The study protocol was approved by the Institutional Review Board of the Ethics Committee of Aichi Medical University Hospital on May 2013. The UMIN clinical trials registry number is UMIN000022492, and the date of registration was May 2016. All patients provided written informed consent before study entry.

\section{Anesthesia}

The anesthesia protocol was standardized for the drugs used during the procedure. Propofol was used for sedation, remifentanil and fentanyl were used for pain relief, and rocuronium was used for muscular relaxation. The lungs were mechanically ventilated. We maintained end-tidal $\mathrm{CO}_{2}$ at 30-40 mmHg. The time under anesthesia was recorded.

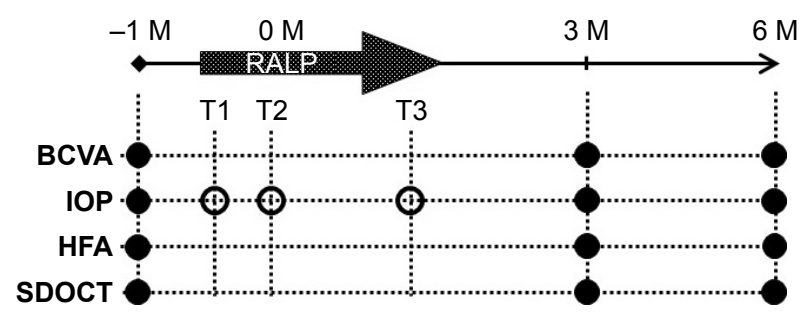

Figure I Outlined time course of when each measurement was performed. Notes: The IOP was measured in sitting position (filled circle), immediately postinduction of anesthesia while in a flat supine position ( $\mathrm{TI}$ ), immediately post-steep Trendelenburg position (T2), and prior to returning to a flat supine position while in a steep Trendelenburg position (T3) (open circle). HFA measured MD and PSD. SDOCT measured GCC, RNFL, and CF thicknesses.

Abbreviations: BCVA, best-corrected visual acuity; CF, central fovea; GCC, ganglion cell complex; HFA, Humphrey field analyzer; IOP, intraocular pressure; $M$, month(s) before and after the surgery; $M D$, mean deviation; PSD, pattern standard deviation; RALP, robotic-assisted laparoscopic radical prostatectomy; RNFL, retinal nerve fiber layer; SDOCT, spectral domain optical coherence tomography. 


\section{Tonometry}

An applanation tonometer was used for IOP monitoring. A slit lamp-mounted Goldmann applanation tonometer (Haag-Streit AG, Koeniz, Switzerland) was used before and after the operation, and a Perkins handheld applanation tonometer (Haag-Streit UK, Harlow, UK) was used during surgery. The Perkins applanation tonometer yields IOP measurements that are closely comparable with those measured with Goldmann applanation tonometry. ${ }^{11}$ On the day of the operation, IOP was measured on each patient in both eyes with a Perkins applanation tonometer. Both eyes were topically anesthetized with two drops of $0.4 \%$ oxybuprocaine hydrochloride (Santen Pharmaceutical Co., Ltd., Osaka, Japan) and stained with fluorescein sodium (Showa Yakuhin Kako Co., Ltd., Tokyo, Japan) before the IOP measurement. The tonometer was calibrated according to the manufacturer's guidelines before each use. A measurement was repeated if the variability between sequential measurements exceeded $5 \%$. The IOP was measured immediately post-induction of anesthesia while in a flat supine position (T1), immediately post-steep Trendelenburg position (T2), and prior to returning to a flat supine position while in a steep Trendelenburg position (T3).

\section{GCC thickness}

The SDOCT RS-3000 system (Nidek Co., LTD., Aichi, Japan) was used, along with the Nidek Advanced Vision Information System (NAVIS) EX version 1.3.0.3. (Nidek Co., LTD.). The GCC thickness was the width between the inner plexiform layer/inner nuclear layer and the inner limiting membrane. The measurement of GCC thickness was calculated automatically by glaucoma analysis in NAVIS, which scanned the macula map program $(9 \times 9 \mathrm{~mm})$. We divided the analysis charts into eight sections (Figure 2). Each GCC sector was divided by two radii $(4.5$ and $9.0 \mathrm{~mm})$ and by four directions (superotemporal, superonasal, inferotemporal, and inferonasal). A circle with a radius of $1.0 \mathrm{~mm}$ was defined as the CF (described below).

\section{RNFL thickness}

The RNFL thickness was the width between the nerve fiber layer/ganglion cell layer complex and the inner limiting membrane circumference, located $3.45 \mathrm{~mm}$ from the center of the optic disc. The measurement of RNFL thickness was calculated automatically by glaucoma analysis in NAVIS, which scanned the optic disc map program $(5.1 \times 5.1 \mathrm{~mm})$. Each RNFL thickness was measured in 12 regions of the optic disc at $30^{\circ}$ intervals along a $3.3 \mathrm{~mm}$ radius for the right eye (Figure 2). A mirror image version was prepared using data obtained from examinations of the left eye. We used the analysis chart, which showed the mean thickness of deviation in the 12 domains.

\section{CF thickness}

A circle with a radius of $1.0 \mathrm{~mm}$ was defined as the CF. The CF thickness was defined as the width between the retinal pigment epithelium/Bruch's membrane complex and the inner limiting membrane. We used a thickness of
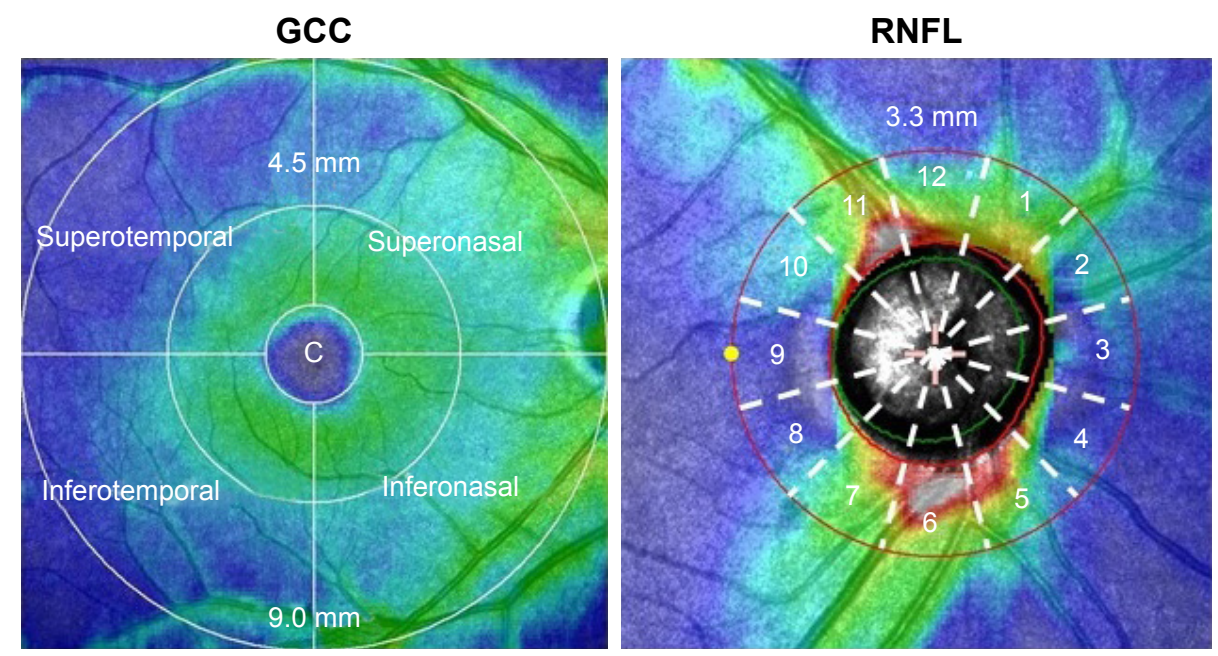

Figure 2 GCC and peripapillary RNFL thicknesses at each sector of the right eye, measured with spectral domain optical coherence tomography.

Notes: Each GCC sector was divided by two radii $(4.5$ and $9.0 \mathrm{~mm}$ ) in four directions (superotemporal, superonasal, inferotemporal, and inferonasal). Each RNFL thickness was measured in 12 regions of the optic disc at $30^{\circ}$ intervals in the $3.3 \mathrm{~mm}$ radius. A mirror image version was prepared using data obtained from examinations of the left eye. c: central fovea to measure the central foveal thickness.

Abbreviations: GCC, ganglion cell complex; RNFL, retinal nerve fiber layer. 
$1.0 \mathrm{~mm}$ in diameter, as calculated automatically by retinal analysis in NAVIS, which scanned the macula map program $(9 \times 9 \mathrm{~mm})$.

\section{Visual field analysis}

Visual field testing was carried out monocularly using the Humphrey field analyzer (Humphrey Instruments, Dublin, CA, USA) and the C-30-2 SITA standard strategy. Test reliability was assessed with the help of Humphrey criteria, such as false positives $(>15 \%)$ and fixation errors $(>25 \%)$. Those whose visual field tests were deemed unreliable according to these criteria were not included in the study. The MD and PSD were used to analyze the results.

\section{Statistical analysis}

The primary outcome measure was the change in IOP in association with RALP. Assuming as a null hypothesis that there is no difference in IOP pre- and post-prostatectomy, we estimated that a sample size of 24 participants was needed to detect a mean change of $1.5 \mathrm{mmHg}$ (standard deviation of $2.5 \mathrm{mmHg}$ ) with $80 \%$ statistical power, using a two-sided one-sample $t$-test at a significance level of 0.05 . Outcome measures (IOP, MD, PSD, GCC, and RNFL thickness values) were analyzed using a mixed-effects model for repeated measures including visit as a factor and eye as a random effect, with the correlation structure modeled as first-order autoregressive. $t$-tests of paired samples from this analysis with Tukey's or Dunnett's multiplicity adjustment were used for mean comparison. To evaluate the relationship between the changes in IOP and patient characteristics (ie, age, body mass index [BMI], and sex), the changes in IOP from baseline were analyzed using a mixed-effects model including age and BMI as fixed effects and eye as a random effect. Sex was not included in this analysis because all patients were male. A value of $P<0.05$ was considered statistically significant, and all statistical analyses were performed with SAS 9.4 (SAS Institute, Cary, NC, USA).

\section{Results}

The study included a total of 44 eyes from 22 men (mean age, $65.0 \pm 6.7$ years; range, $50-75$ years). The mean operation time was $5.46 \mathrm{~h} \pm 60.3 \mathrm{~min}$ (range, $3 \mathrm{~h} 52 \mathrm{~min}-7 \mathrm{~h} 41 \mathrm{~min}$ ). The operation time was defined as the time from entering to leaving the operation room. Mean blood loss was $350 \pm 343 \mathrm{~mL}$ (range, 50-1,700 mL). Mean visual acuity (logarithm of the minimal angle of resolution) was -0.02 preoperatively and -0.01 and -0.02 at 3 and 6 months postoperatively, respectively, with no statistically significant
Table I Intraocular pressure measurements performed immediately post-induction of anesthesia while in flat supine position (TI), immediately post-steep Trendelenburg position (T2), and prior to returning to the supine position while in a steep Trendelenburg position (T3)

\begin{tabular}{lll}
\hline Defined time points & Mean $(95 \% \mathrm{CI})$ \\
\hline TI & & $10.4(8.3,12.5)$ \\
T2 & $21.7(19.7,23.8)$ \\
T3 & $29.6(27.6,31.5)$ \\
\hline Transition & Difference $(95 \% \mathrm{CI})$ & $P$-value \\
\hline T2-TI & II.3 $(9.4,13.3)$ & $<0.00 \mathrm{I}$ \\
T3-TI & $19.1(16.8,21.5)$ & $<0.00 \mathrm{I}$ \\
T3-T2 & $7.8(6.0,9.7)$ & $<0.00 \mathrm{I}$ \\
\hline
\end{tabular}

Notes: aPairwise comparison among the three positions was performed by $t$-tests of paired samples from a mixed-effects model for repeated measures with Tukey's multiplicity adjustment.

difference found before and after the operation. The mean IOPs (T1, T2, and T3) during surgery, measured with the Perkins applanation tonometer, were 10.4, 21.7, and $29.6 \mathrm{mmHg}$, respectively (Table 1). Each IOP was significantly different from the other IOPs.

The IOP measured with Goldmann applanation tonometry before and after surgery showed no significant difference (Table 2). The MD and PSD measured by the Humphrey field analyzer before and after surgery also showed no significant difference, except that the MD improved at each visit; however, the difference was statistically significant at 6 months after RALP, probably because of a learning effect (Table 2). The GCC thicknesses at each location, measured

Table 2 IOP measured with Goldmann applanation tonometry, and MD and PSD measured by Humphrey field analyzer before and after the operation

\begin{tabular}{|c|c|c|c|c|}
\hline Variable & $\begin{array}{l}\text { Visit } \\
\text { (months) }\end{array}$ & Mean $(95 \% \mathrm{Cl})$ & $\begin{array}{l}\text { Difference } \\
(95 \% \mathrm{Cl})\end{array}$ & $P$-value ${ }^{a}$ \\
\hline \multicolumn{5}{|l|}{$\mathrm{IOP}$} \\
\hline & 0 & $13.5(|2.6| 4.5)$, & - & - \\
\hline & 3 & $13.4(12.5,14.4)$ & $-0.1(-0.9,0.7)$ & 0.96 \\
\hline & 6 & $12.9(11.9,13.9)$ & $-0.6(-1.6,0.3)$ & 0.34 \\
\hline \multicolumn{5}{|l|}{ MD } \\
\hline & 0 & $-1.11(-2.14,-0.09)$ & - & - \\
\hline & 3 & $-0.64(-1.71,0.42)$ & $0.47(-0.21,1.15)$ & 0.29 \\
\hline & 6 & $-0.13(-1.22,0.95)$ & $0.98(0.20,1.76)$ & 0.027 \\
\hline \multicolumn{5}{|l|}{ PSD } \\
\hline & 0 & $3.11(2.86,3.37)$ & - & - \\
\hline & 3 & $2.95(2.67,3.22)$ & $-0.17(-0.39,0.05)$ & 0.22 \\
\hline & 6 & $2.90(2.62,3.18)$ & $-0.21(-0.46,0.04)$ & 0.17 \\
\hline
\end{tabular}

Notes: ${ }^{a}$ Comparison between before and after the operation was performed with $t$-tests of paired samples from a mixed-effects model for repeated measures with Dunnett's multiplicity adjustment.

Abbreviations: IOP, intraocular pressure; MD, mean deviation; PSD, pattern standard deviation. 
Table 3 GCC thickness at each location measured with spectral domain optical coherence tomography before and after the operation

\begin{tabular}{|c|c|c|c|c|}
\hline Variable $^{a}$ & $\begin{array}{l}\text { Visit } \\
\text { (months) }\end{array}$ & Mean $(95 \% \mathrm{Cl})$ & $\begin{array}{l}\text { Difference } \\
(95 \% \mathrm{Cl})\end{array}$ & $P$-value ${ }^{b}$ \\
\hline \multicolumn{5}{|l|}{ 9.0_ST } \\
\hline & 0 & $67.7(64.9,70.5)$ & - & - \\
\hline & 3 & $68.0(65.1,70.8)$ & $0.3(-1.6,2.2)$ & 0.93 \\
\hline & 6 & $68.7(65.8,71.7)$ & $1.0(-1.5,3.5)$ & 0.60 \\
\hline \multicolumn{5}{|l|}{ 9.0_SN } \\
\hline & 0 & $102.4(99.2,105.6)$ & - & - \\
\hline & 3 & I03.I (99.8, I06.4) & $0.7(-1.1,2.4)$ & 0.66 \\
\hline & 6 & $103.9(100.6,107.2)$ & $1.5(-0.3,3.3)$ & 0.19 \\
\hline \multicolumn{5}{|l|}{ 9.0_IT } \\
\hline & 0 & $70.5(67.9,73.0)$ & - & - \\
\hline & 3 & $70.9(68.3,73.6)$ & $0.5(-1.4,2.4)$ & 0.82 \\
\hline & 6 & $71.3(68.5,74.1)$ & $0.8(-1.7,3.3)$ & 0.71 \\
\hline \multicolumn{5}{|l|}{ 9.0_IN } \\
\hline & 0 & $108.3(|04.6,1| 1.9)$ & - & - \\
\hline & 3 & I07.I (I03.4, II0.8) & $-1.1(-2.9,0.7)$ & 0.38 \\
\hline & 6 & $109.2(105.6,112.9)$ & $1.0(-0.4,2.4)$ & 0.29 \\
\hline \multicolumn{5}{|l|}{ 4.5_ST } \\
\hline & 0 & $100.5(97.6,103.4)$ & - & - \\
\hline & 3 & I0I.7 (98.7, 104.7) & $1.2(-0.7,3.0)$ & 0.33 \\
\hline & 6 & $100.0(96.9,103.1)$ & $-0.5(-3.1,2.1)$ & 0.88 \\
\hline \multicolumn{5}{|l|}{ 4.5_SN } \\
\hline & 0 & II $2.8(I I 0.1,115.5)$ & - & - \\
\hline & 3 & II $2.9(110.2,115.6)$ & $0.1(-1.0,1.2)$ & 0.98 \\
\hline & 6 & II $4.0(1 \mid 1.2,116.7)$ & $1.2(0.0,2.3)$ & 0.10 \\
\hline \multicolumn{5}{|l|}{ 4.5_IT } \\
\hline & 0 & $105.0(102.6,107.4)$ & - & - \\
\hline & 3 & $105.2(102.6,107.8)$ & $0.2(-2.2,2.6)$ & 0.98 \\
\hline & 6 & $103.1(100.4,105.9)$ & $-1.9(-5.0,1.3)$ & 0.38 \\
\hline \multicolumn{5}{|l|}{ 4.5_IN } \\
\hline & 0 & II $2.9(\mid 10.4$, II5.3) & - & - \\
\hline & 3 & II $2.9(110.4,115.4)$ & $0.0(-1.2,1.1)$ & 1.00 \\
\hline & 6 & II $2.8(\mathrm{II0.2,} \mathrm{II5.4)}$ & $-0.1(-1.7,1.6)$ & 0.99 \\
\hline \multicolumn{5}{|c|}{ GCC_global } \\
\hline & 0 & $780.0(761.6,798.4)$ & - & - \\
\hline & 3 & $782.0(763.4,800.7)$ & $2.1(-6.0,10.1)$ & 0.81 \\
\hline & 6 & $783.6(764.5,802.6)$ & $3.6(-7.4,14.6)$ & 0.72 \\
\hline
\end{tabular}

Notes: a9.0: $9.0 \mathrm{~mm}$ radius; 4.5: $4.5 \mathrm{~mm}$ radius. ${ }^{\mathrm{b}}$ Comparison between before and after the operation was performed by $t$-tests of paired samples from a mixed-effects model for repeated measures with Dunnett's multiplicity adjustment.

Abbreviations: GCC, ganglion cell complex; IN, inferonasal; IT, inferotemporal; SN, superonasal; ST, superotemporal.

with SDOCT before and after the operation, were not significantly different (Table 3 ).

The peripapillary RNFL thicknesses at each location, measured with SDOCT before and after the operation, were analyzed. Thicknesses measured at each location before and at 3 and 6 months after surgery were not significantly different (Table 4). In addition, the CF thickness measured with SDOCT before and after the operation was also analyzed, and the mean foveal thicknesses before and at 3 and
Table 4 Peripapillary RNFL at each location, measured with spectral domain optical coherence tomography before and after the operation

\begin{tabular}{|c|c|c|c|c|}
\hline Variable $^{a}$ & $\begin{array}{l}\text { Visit } \\
\text { (months) }\end{array}$ & Mean $(95 \% \mathrm{Cl})$ & $\begin{array}{l}\text { Difference } \\
(95 \% \mathrm{Cl})\end{array}$ & $P$-value \\
\hline \multicolumn{5}{|l|}{ RNFL_I } \\
\hline & 0 & $108.9(102.6,115.2)$ & - & - \\
\hline & 3 & $110.9(104.4,117.3)$ & $2.0(-1.5,5.4)$ & 0.41 \\
\hline & 6 & II $0.4(103.9,116.9)$ & I.5 $(-2.5,5.5)$ & 0.66 \\
\hline \multicolumn{5}{|l|}{ RNFL_2 } \\
\hline & 0 & $81.8(76.8,86.9)$ & - & - \\
\hline & 3 & $82.7(77.2,88.1)$ & $0.8(-3.9,5.5)$ & 0.91 \\
\hline & 6 & $85.4(79.9,90.9)$ & $3.6(-1.3,8.4)$ & 0.26 \\
\hline \multicolumn{5}{|l|}{ RNFL_3 } \\
\hline & 0 & $59.8(54.8,64.9)$ & - & - \\
\hline & 3 & $61.8(56.4,67.3)$ & $2.0(-2.9,6.9)$ & 0.64 \\
\hline & 6 & $61.8(56.3,67.4)$ & $2.0(-2.8,6.9)$ & 0.62 \\
\hline \multicolumn{5}{|l|}{ RNFL_4 } \\
\hline & 0 & $62.4(58.3,66.5)$ & - & - \\
\hline & 3 & $66.7(62.1,71.2)$ & $4.3(-1.5,10.1)$ & 0.25 \\
\hline & 6 & $65.9(61.1,70.6)$ & $3.5(-2.6,9.5)$ & 0.42 \\
\hline \multicolumn{5}{|l|}{ RNFL_5 } \\
\hline & 0 & $100.4(94.6,106.1)$ & - & - \\
\hline & 3 & 98.1 (92.I, I04.I) & $-2.2(-6.2,1.7)$ & 0.42 \\
\hline & 6 & $99.1(93.0,105.1)$ & $-1.3(-5.3,2.7)$ & 0.74 \\
\hline \multicolumn{5}{|l|}{ RNFL_6 } \\
\hline & 0 & $144.5(136.0,152.9)$ & - & - \\
\hline & 3 & I44.8 (I36.I, I53.5) & $0.4(-4.3,5.1)$ & 0.98 \\
\hline & 6 & $145.2(136.6,153.9)$ & $0.8(-2.9,4.5)$ & 0.88 \\
\hline \multicolumn{5}{|l|}{ RNFL_7 } \\
\hline & 0 & I27.7 (I20.4, I34.9) & - & - \\
\hline & 3 & $130.2(122.6,137.7)$ & $2.5(-1.8,6.8)$ & 0.42 \\
\hline & 6 & $128.2(\mid 20.6,135.7)$ & $0.5(-3.9,4.9)$ & 0.97 \\
\hline \multicolumn{5}{|l|}{ RNFL_8 } \\
\hline & 0 & $63.3(59.8,66.8)$ & - & - \\
\hline & 3 & $62.7(59.0,66.4)$ & $-0.6(-3.1,1.9)$ & 0.83 \\
\hline & 6 & $62.1(58.3,65.9)$ & $-1.2(-4.4,2.0)$ & 0.65 \\
\hline \multicolumn{5}{|l|}{ RNFL_9 } \\
\hline & 0 & $55 . I(52.7,57.6)$ & - & - \\
\hline & 3 & $53.1(50.6,55.7)$ & $-2.0(-3.9,-0.1)$ & 0.077 \\
\hline & 6 & $53.3(50.8,55.9)$ & $-1.8(-3.4,-0.2)$ & 0.057 \\
\hline \multicolumn{5}{|l|}{ RNFL_I0 } \\
\hline & 0 & $76.6(72.3,80.8)$ & - & - \\
\hline & 3 & $73.4(69.0,77.8)$ & $-3.2(-6.1,-0.3)$ & 0.060 \\
\hline & 6 & $74.4(70.0,78.7)$ & $-2.2(-4.4,0.0)$ & 0.097 \\
\hline \multicolumn{5}{|l|}{ RNFL_II } \\
\hline & 0 & $123.5(|15.9| 3 \mid .0)$, & - & - \\
\hline & 3 & $126.0(|| 8.3,133.8)$ & $2.6(-1.6,6.8)$ & 0.35 \\
\hline & 6 & $124.6(\mid 16.8,132.5)$ & $1.2(-3.7,6.0)$ & 0.84 \\
\hline \multicolumn{5}{|l|}{ RNFL_I2 } \\
\hline & 0 & $124.6(\mid 16.8,132.4)$ & - & - \\
\hline & 3 & $121.8(1 \mid 3.8,129.8)$ & $-2.8(-7.0,1.4)$ & 0.31 \\
\hline & 6 & $125.6(117.5,133.7)$ & $\mathrm{I} .0(-3.8,5.8)$ & 0.88 \\
\hline
\end{tabular}

Notes: ${ }^{2}$ Clock direction at $30^{\circ}$ intervals at the optic disc for the right eye. A mirror image was used for examinations of the left eye. ${ }^{b}$ Comparison between before and after the operation was performed by $t$-tests of paired samples from a mixed-effects model for repeated measures with Dunnett's multiplicity adjustment.

Abbreviation: RNFL, retinal nerve fiber layer. 
Table 5 Central fovea thickness measured with spectral domain optical coherence tomography before and after the operation

\begin{tabular}{lllll}
\hline Variable & $\begin{array}{l}\text { Visit } \\
\text { (months) }\end{array}$ & Mean $(\mathbf{9 5 \%} \mathbf{C l})$ & $\begin{array}{l}\text { Difference } \\
(\mathbf{9 5 \%} \mathbf{C l})\end{array}$ & P-value $^{\mathbf{a}}$ \\
\hline Fovea & 0 & $273.7(265.6,281.8)$ & - & - \\
& 3 & $272.9(264.8,281.1)$ & $-0.7(-3.4,1.9)$ & 0.78 \\
& 6 & $273.8(265.5,282.0)$ & $0.1(-3.4,3.6)$ & 1.00 \\
\hline
\end{tabular}

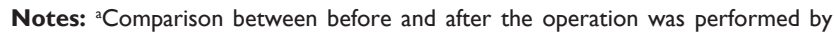
$t$-tests of paired samples from a mixed-effects model for repeated measures with Dunnett's multiplicity adjustment.

6 months after the operation were not significantly different (Table 5). Also, there was no significant relationship between the changes in IOP and the baseline parameters (age and BMI) in this cohort (Table 6).

\section{Discussion}

Data of this study support that IOP significantly increases in a time-dependent manner after steep Trendelenburg positioning in anesthetized patients undergoing RALP, as previously reported. ${ }^{4,5,7}$ Furthermore, we demonstrated no statistically significant changes in ocular structural parameters and visual functions after RALP. Two prior reports examined the change in RNFL thickness before and after steep Trendelenburg positioning in anesthetized patients undergoing RALP., Although Taketani et al demonstrated transient but significant visual field defects, RNFL showed no statistically significant difference after RALP. In these previous studies, the RNFL parameters, average RNFL thickness, superior RNFL thickness, and inferior RNFL thickness were analyzed with the Cirrus HD-OCT (Carl Zeiss Meditec, Inc., Dublin, CA, USA), and the RNFL thickness was examined at 1 month $^{7}$ and 7-10 days ${ }^{4}$ postoperatively. We previously showed that the superotemporal sector has the strongest relationship with the threshold of visual sensitivity and total deviation of the visual field in the structural parameters examined in glaucoma patients, ${ }^{12}$ but no significant changes were demonstrated in this sector after RALP in this study. This outcome may suggest that a steep Trendelenburg positioning during RALP does not induce glaucomatous change.

Positioning of the patient is important when determining IOP during surgery, although the precise mechanism for this is still unclear. During steep Trendelenburg positioning in anesthetized patients undergoing RALP, we measured IOP for three defined time points. Prior reports also showed a transition of IOP. ${ }^{4,5,7}$ Our average IOPs $(\mathrm{mmHg})$ for each time point were $\mathrm{T} 1=10.4, \mathrm{~T} 2=21.7$, and $\mathrm{T} 3=29.6$. For the same time points, Awad et al reported IOPs of $\mathrm{T} 1=10.7$, $\mathrm{T} 2=25.2$, and $\mathrm{T} 3=29.0{ }^{5}$ Hoshikawa et al reported IOPs of $\mathrm{T} 1=9.8, \mathrm{~T} 2=18.9$, and $\mathrm{T} 3=24.0{ }^{7}$ and Taketani et al reported IOPs of $\mathrm{T} 1=11.0, \mathrm{~T} 2=21.2$, and $\mathrm{T} 3=29.4{ }^{4}$ All data demonstrated the lowest value at T1 and the highest at T3 and similar transitions of IOP. This time-dependent increase in IOP in the steep Trendelenburg position is similar to previous reports. ${ }^{6,13}$

Similarly, the IOP of patients increased in the prone position. ${ }^{14-16}$ Of interest, the mean IOP in the prone Trendelenburg position was significantly higher than in the prone flat position. ${ }^{15}$ Carey et al showed that reverse Trendelenburg positioning elicits decreased IOP compared with prone positioning, ${ }^{17}$ while Grant et al showed that reverse Trendelenburg positioning does not attenuate the increase in IOP compared with the prone flat position. ${ }^{16}$

Multiple perioperative factors are believed to be involved in controlling the increase in IOP during surgery. Possible candidates are ventral venous pressure, ${ }^{18}$ pneumoperitoneum, ${ }^{19}$ anesthetic induction agents, ${ }^{13}$ choroidal thickness, and optic nerve diameter. ${ }^{16}$ There is an increase in intracranial pressure during carbon dioxide pneumoperitoneum with steep Trendelenburg positioning, ${ }^{20}$ and it may have a negative effect on the optic nerve head, although RALP in the Trendelenburg position does not impair cerebral oxygenation. ${ }^{21}$ Recently, Yoo et al demonstrated that propofol and continuous deep

Table 6 Regression analysis for change in IOP at 3 and 6 months

\begin{tabular}{|c|c|c|c|c|}
\hline \multirow[t]{2}{*}{ Variable } & \multicolumn{2}{|l|}{ Univariate analysis } & \multicolumn{2}{|l|}{ Multivariate analysis } \\
\hline & $\begin{array}{l}\text { Regression coefficient } \\
(95 \% \mathrm{Cl})\end{array}$ & $P$-value & $\begin{array}{l}\text { Regression coefficient } \\
(95 \% \mathrm{Cl})\end{array}$ & $P$-value \\
\hline \multicolumn{5}{|l|}{3 months } \\
\hline Age ( 10 years) & $0.89(-0.60,2.39)$ & 0.22 & $1.60(-0.61,3.81)$ & 0.13 \\
\hline BMI $(I$ kg/m²) & $-0.19(-0.75,0.36)$ & 0.45 & $-0.34(-0.92,0.24)$ & 0.21 \\
\hline \multicolumn{5}{|l|}{6 months } \\
\hline Age ( 10 years) & $0.34(-1.23,1.90)$ & 0.65 & $1.27(-1.11,3.65)$ & 0.25 \\
\hline BMI $(I$ kg/m²) & $-0.09(-0.91,0.74)$ & 0.82 & $-0.19(-1.05,0.67)$ & 0.62 \\
\hline
\end{tabular}

Abbreviations: BMI, body mass index; IOP, intraocular pressure. 
neuromuscular blockade have beneficial influences on IOP during RALP. ${ }^{13,22}$ In addition, Raz et al modified the Trendelenburg position during RALP to minimize the increase in IOP. ${ }^{23}$

The operation time is a critical risk factor, is closely correlated with the increase in IOP in most cases, ${ }^{2,5-7,13-16}$ and might be involved in postoperative visual loss. Weber et al first reported a case of a 62-year-old patient who developed ION after a robotic-assisted procedure lasting $6 \mathrm{~h} 35 \mathrm{~min}$. ${ }^{1}$ Patel et al reported the mean operation time from skin incision to fascial closure was $105 \mathrm{~min}$ (range, 55-300). ${ }^{24}$ In this study, the mean was $5.46 \mathrm{~h} \pm 60.3 \mathrm{~min}$, which we estimate was longer than average, but similar to the $5.3 \pm 1.0 \mathrm{~h}$ reported by Taketani et al. ${ }^{4}$ Although definitive evidence is lacking, the quantity of blood loss also may be a risk for the occurrence of ION. Patel et al reported the mean estimated blood loss from 1,500 consecutive cases was $111 \mathrm{~mL}$ (range, 50-500 mL). ${ }^{24}$ In a 62-year-old patient who developed ION, the blood loss was 1,200 mL. ${ }^{1}$ In this study, the mean blood loss was $350 \pm 343 \mathrm{~mL}$, with no ION.

There are several precipitating factors for postoperative vision loss. ${ }^{25}$ The incidence is greater in patients with preexisting hypertension, diabetes, sickle cell anemia, renal failure, gastrointestinal ulcer, narrow-angle glaucoma, vascular occlusive disease, cardiac disease, arteriosclerosis, polycythemia vera, and collagen vascular disorders. In addition, ION, retinal artery occlusion, cortical blindness, and ophthalmic venous obstruction may lead to postoperative vision loss. In this study, four patients were treated for hypertension, but we found no ocular complications at any of the examinations. It should be mentioned that the relatively small number of enrolled patients in this study limits the conclusions. A complete ophthalmic examination was performed only three times, before surgery and at 3 and 6 months afterward. Thus, further study is needed to evaluate the ocular structural and functional parameters more precisely before and after RALP.

RALP may be one of the causes of surgical posterior ION (PION). Etiologically, surgical PION is classified as a complication of several systemic surgical procedures. ${ }^{26}$ A wide variety of optic nerve-related visual field defects have been reported in PION. The most common visual field defect is central visual loss, alone or in combination with other types of visual field defects. Taketani et al demonstrated postoperative local visual field defects using the Humphrey visual field analyzer with the 30-2 SITA-standard program in subjects dominantly in the lower hemifield without abnormal findings in the optic nerve head or retina, and the visual field recovered to normal within 3 months after surgery. ${ }^{4}$ Although no visual field abnormality was found, the tendency of decreased temporal RNFL thickness after RALP shown in our study may be involved in a late-onset disorder by the surgical PION. However, our study numbers were small, and the tendency to our measured parameters is limited.

\section{Conclusion}

There was no detectable disorder of ocular structural parameters as evaluated by the thicknesses of the peripapillary RNFL, GCC, and CF measured with SDOCT or of visual function as evaluated by BCVA, MD, and PSD at 3 and 6 months, the longest postsurgical period ever reported. Our study data confirm previous reports that IOP is significantly increased in a time-dependent manner in patients undergoing RALP in a steep Trendelenburg position. The increase in IOP induced by the patient's position during the operation was not associated with pathologic progression.

\section{Acknowledgments}

The authors wish to acknowledge Dr Kogenta Nakamura, Department of Urology, Aichi Medical University, and the staff involved in the study for their assistance. No financial support was received for this research.

\section{Disclosure}

The authors report no conflicts of interest in this work.

\section{References}

1. Weber ED, Colyer MH, Lesser RL, Subramanian PS. Posterior ischemic optic neuropathy after minimally invasive prostatectomy. J Neuroophthalmol. 2007;27(4):285-287.

2. Molloy BL. Implications for postoperative visual loss: steep trendelenburg position and effects on intraocular pressure. AANA J. 2011;79(2): $115-121$.

3. Kumar G, Vyakarnam P. Postoperative vision loss after colorectal laparoscopic surgery. Surg Laparosc Endosc Percutan Tech. 2013;23(2): e87-e88.

4. Taketani Y, Mayama C, Suzuki N, et al. Transient but significant visual field defects after robot-assisted laparoscopic radical prostatectomy in deep tRendelenburg position. PLoS One. 2015;10(4):e0123361.

5. Awad H, Santilli S, Ohr M, et al. The effects of steep trendelenburg positioning on intraocular pressure during robotic radical prostatectomy. Anesth Analg. 2009;109(2):473-478.

6. Borahay MA, Patel PR, Walsh TM, et al. Intraocular pressure and steep Trendelenburg during minimally invasive gynecologic surgery: is there a risk? J Minim Invasive Gynecol. 2013;20(6):819-824.

7. Hoshikawa Y, Tsutsumi N, Ohkoshi K, et al. The effect of steep Trendelenburg positioning on intraocular pressure and visual function during robotic-assisted radical prostatectomy. Br J Ophthalmol. 2014;98(3): 305-308.

8. Liu X, Li M, Zhong Y, Xiao H, Huang J, Mao Z. The damage patterns of retinal nerve fiber layer in acute and chronic intraocular pressure elevation in primary angle closure glaucoma. Eye Sci. 2011;26(3):154-160. 
9. Chew SS, Vasudevan S, Patel HY, et al. Acute primary angle closure attack does not cause an increased cup-to-disc ratio. Ophthalmology. 2011;118(2):254-259.

10. Bonomi L, Marraffa M, Marchini G, Canali N. Perimetric defects after a single acute angle-closure glaucoma attack. Graefes Arch Clin Exp Ophthalmol. 1999;237(11):908-914.

11. Arora R, Bellamy H, Austin M. Applanation tonometry: a comparison of the Perkins handheld and Goldmann slit lamp-mounted methods. Clin Ophthalmol. 2014;8:605-610.

12. Mizumoto K, Gosho M, Zako M. Correlation between optic nerve head structural parameters and glaucomatous visual field indices. Clin Ophthalmol. 2014;8:1203-1208.

13. Yoo YC, Shin S, Choi EK, Kim CY, Choi YD, Bai SJ. Increase in intraocular pressure is less with propofol than with sevoflurane during laparoscopic surgery in the steep Trendelenburg position. Can J Anaesth. 2014;61(4):322-329.

14. Cheng MA, Todorov A, Tempelhoff R, McHugh T, Crowder CM, Lauryssen $\mathrm{C}$. The effect of prone positioning on intraocular pressure in anesthetized patients. Anesthesiology. 2001;95(6):1351-1355.

15. Walick KS, Kragh JE Jr, Ward JA, Crawford JJ. Changes in intraocular pressure due to surgical positioning: studying potential risk for postoperative vision loss. Spine (Phila Pa 1976). 2007;32(23):2591-2595.

16. Grant GP, Szirth BC, Bennett HL, et al. Effects of prone and reverse trendelenburg positioning on ocular parameters. Anesthesiology. 2010; 112(1):57-65.

17. Carey TW, Shaw KA, Weber ML, Devine JG. Effect of the degree of reverse Trendelenburg position on intraocular pressure during prone spine surgery: a randomized controlled trial. Spine J. 2014;14(9): 2118-2126.

18. Robert YC, Dekker PW, Battig U, Kochli OR, Alon E. Measurement of intraocular pressure during laparoscopy and its relationship to central venous pressure. J Am Assoc Gynecol Laparosc. 1998;5(2):125-128.
19. Grosso A, Scozzari G, Bert F, Mabilia MA, Siliquini R, Morino M. Intraocular pressure variation during colorectal laparoscopic surgery: standard pneumoperitoneum leads to reversible elevation in intraocular pressure. Surg Endosc. 2013;27(9):3370-3376.

20. Kim MS, Bai SJ, Lee JR, Choi YD, Kim YJ, Choi SH. Increase in intracranial pressure during carbon dioxide pneumoperitoneum with steep trendelenburg positioning proven by ultrasonographic measurement of optic nerve sheath diameter. J Endourol. 2014;28(7):801-806.

21. Closhen D, Treiber AH, Berres M, et al. Robotic assisted prostatic surgery in the Trendelenburg position does not impair cerebral oxygenation measured using two different monitors: a clinical observational study. Eur J Anaesthesiol. 2014;31(2):104-109.

22. Yoo YC, Kim NY, Shin S, et al. The intraocular pressure under deep versus moderate neuromuscular blockade during low-pressure robot assisted laparoscopic radical prostatectomy in a randomized trial. PLoS One. 2015;10(8):e0135412.

23. Raz O, Boesel TW, Arianayagam M, et al. The effect of the modified Z trendelenburg position on intraocular pressure during robotic assisted laparoscopic radical prostatectomy: a randomized, controlled study. J Urol. 2015;193(4):1213-1219.

24. Patel VR, Palmer KJ, Coughlin G, Samavedi S. Robot-assisted laparoscopic radical prostatectomy: perioperative outcomes of 1500 cases. J Endourol. 2008;22(10):2299-2305.

25. Rupp-Montpetit K, Moody ML. Visual loss as a complication of nonophthalmologic surgery: a review of the literature. AANA J. 2004; 72(4):285-292.

26. Hayreh SS. Ischemic optic neuropathy. Prog Retin Eye Res. 2009; 28(1):34-62.
Clinical Ophthalmology

\section{Publish your work in this journal}

Clinical Ophthalmology is an international, peer-reviewed journal covering all subspecialties within ophthalmology. Key topics include: Optometry; Visual science; Pharmacology and drug therapy in eye diseases; Basic Sciences; Primary and Secondary eye care; Patient Safety and Quality of Care Improvements. This journal is indexed on Submit your manuscript here: http://www.dovepress.com/clinical-ophthalmology-journal

\section{Dovepress}

PubMed Central and CAS, and is the official journal of The Society of Clinical Ophthalmology (SCO). The manuscript management system is completely online and includes a very quick and fair peer-review system, which is all easy to use. Visit http://www.dovepress.com/ testimonials.php to read real quotes from published authors. 